\title{
Contamination level and risk assessment of heavy metals in the topsoil around cement factory: A case study
}

\author{
Hamid Amiri ${ }^{+}$, Ehsan Daneshvar ${ }^{2}$, Sama Azadi ${ }^{3}$, Samira Azadi ${ }^{4}$ \\ ${ }^{1}$ School Department of Civil and Environmental Engineering, Tarbiat Modares University, Tehran, Iran \\ ${ }^{2}$ Department of Civil Engineering, Shiraz Payam Noor University, Shiraz, Iran \\ ${ }^{3}$ Department of Civil Engineering, Ferdowsi University of Mashhad, Mashhad, Iran \\ ${ }^{4}$ eWater Ltd, Canberra, Australian Capital Territory (ACT), Australia
}

\begin{abstract}
The cement industry is considered as a major source of heavy metals pollution in topsoil. This study aims at measuring the heavy metal contamination level in the vicinity of Shiraz cement factory, and assessing the ecological and environmental risks associated with the factory's activities in the surrounding topsoil. To do so, 10 samples of soil were taken from around the Shiraz cement factory at the depth of 0-10 cm and the concentration of some heavy metals including $\mathrm{Al}, \mathrm{Cd}, \mathrm{Ni}$, and $\mathrm{Pb}$ was measured. Enrichment factor (EF), geo-accumulation (Igeo), and pollution load (PLI) indices were used to assess the ecological risk of heavy metals.Based on the results, the mean concentration of $\mathrm{Al}, \mathrm{Ni}, \mathrm{Cd}$, and $\mathrm{Pb}$ was $6,937.14$ $88.09,1.96$, and $30.74 \mathrm{mg} / \mathrm{kg}$, respectively. The EF results showed that due to anthropogenic activities, the $\mathrm{Ni}$, $\mathrm{Pb}$, and $\mathrm{Cd}$ element has moderate, severe, and very severe enrichment in the study area, respectively. The Igeo result for $\mathrm{Al}, \mathrm{Ni}, \mathrm{Pb}$, and $\mathrm{Cd}$ was $-0.82,-0.17,0.16$, and 0.68 , respectively, which indicates non- to slightly pollution of these heavy metals in this region. The mean PLI in the study area was 1.4 indicating the low to medium pollution of heavy metal. The results of this study can be useful in determining and investigating the environmental effects of Shiraz cement factory.
\end{abstract}

Keywords: Enrichment factor, Heavy metals, Land accumulation index, Shiraz Cement Factory, Soil pollution

\section{Introduction}

One of the most important factors in the deterioration of soil physical and chemical properties is human activities such as mining, industry, agriculture, transport, and waste disposal [1-3]. Cement industry, as a basic and strategic industry which plays crucial role in the development of different countries, makes a major contribution to increase environmental pollution through the release of heavy metals. According to the United States Central Pollution Control Board list, the cement industry is one of the seventeen polluting industries [4]. The main pollutants emitted from cement factories include particulate matters, heavy metals, $\mathrm{SO}_{x}$, and $\mathrm{NO}_{2}$ [5]. Heavy metals emitted from the smokestacks of cement factories can cause the soil around cement factory to be polluted with non-degradable contaminants. The extent of pollution depends on the wind speed and direction, particle size, and land-use type [6, 7] In addition, the physical and chemical properties of soil, such as $\mathrm{pH}$, sand and clay ratio, the amount of carbonate minerals and organic matter, cation exchangeability, the type of clay minerals and silicon, and $\mathrm{Al}$ and $\mathrm{Fe}$ oxides content affect the absorption rate of heavy metals into the soil [8]. Even if the emission of heavy metals by the cement industry is low, it will have significant effects on plants, water resources, and surrounding environment. So, the amount of different heavy metals such as $\mathrm{Ni}, \mathrm{Pb}, \mathrm{Cd}, \mathrm{Cr}, \mathrm{Zn}, \mathrm{Cu}$, and $\mathrm{Al}$ in the soil around cement factories have to be monitored and assessed [9-19].

To study the ecological and environmental risks of soil polluted with heavy metals, different indicators such as Igeo, PLI, EF, and potential ecological risk index (ERI) have been developed [14, 17, 20-24]. PLI and ERI evaluate the combined risk of multiple trace elements in soil while EF shows the relative enrichment in any contaminant in comparison to pre-industrial soils from the same environment [25]. In addition, Igeo indicates the accumulation effect of heavy metals in respect to the background natural levels
This is an Open Access article distributed under the terms of the Creative Commons Attribution Non-Commercial License (http://creativecommons.org/licenses/by-nc/3.0/) which permits unrestricted non-commercial use, distribution, and reproduction in any medium, provided the original work is properly cited.

Copyright (C) 2022 Korean Society of Environmental Engineers
Received July 5, 2021 Accepted November 7, 2021

${ }^{\dagger}$ Corresponding author

E-mail: hamid64amiri@gmail.com

Tel: +989360694985 Fax: +987138391994

ORCID: 0000-0001-9169-9619 
of the elements. Since the indicators represent different concepts about heavy metals, the use of different indicators in evaluating the effects of cement factory is necessary. Odoh et al. [12] used Igeo, EF, and PLI indices to evaluate the effects of the Obajana cement factory in Nigeria. According to the EF index, soil samples around the factory were not enriched, while Igeo and PLI results showed that some heavy metals were in the high pollution class at most sites. Laniyan and Adewumi [22] used the Igeo, PLI, and ERI to assess the contamination and ecological risk of heavy metals in the soil and plants around the Lafarge cement production factory (Ewekoro, Nigeria). The value of Igeo, PLI, and ERI in their study area was between -0.15 and $6.32,1.37$ and 23.76 , and 49.71 and 749 , respectively. Olatunde et al. [21] assessed the ecological risk of heavy metals in soil around Ibase cement factory (Ogun State, Nigeria) using ERI and Igeo indices. Based on their results, while the ecological risk of $\mathrm{Cd}$ in the soil around the factory was moderate to high and the risk of $\mathrm{Pb}$ was moderate, the amount of other elements in the soil around the factory was insignificant. Although, some studies have been conducted in this respect, there are currently no published papers analyzing the heavy metals of soil around cement factory in Shiraz City, Iran. Therefore, the purpose of this study is to investigate the degree and distribution of pollution risk of heavy metals in soil around Shiraz cement factory (Fars, Iran) which is located near many orange and pomegranate gardens. To do so, in this paper, the concentration of $\mathrm{Cd}, \mathrm{Ni}, \mathrm{Pb}$, and $\mathrm{Al}$ was first measured in 10 soil samples around Shiraz cement factory. Then, the ecological and environmental effects of these contaminants on soil resources were investigated by computing the Igeo, EF, and PLI indices.

\section{Materials and Methods}

\subsection{Case Study}

Shiraz cement factory covers 140 ha and lies between $29^{\circ} 37^{\prime} 20^{\prime \prime}$ $\mathrm{N}$ to $29^{\circ} 37^{\prime} 40^{\prime \prime} \mathrm{N}$ latitude and $52^{\circ} 27^{\prime} 00^{\prime \prime} \mathrm{E}$ to $29^{\circ} 37^{\prime} 40^{\prime \prime} \mathrm{E}$ longitude in the southwest of Shiraz City in Fars Province, Iran (Fig. 1). This city is famous for its gardens that are of great importance in terms of environment, ecology, and tourist attraction. Shiraz cement factory started the exploitation activities in 1965 and produces 200 tons of cement per day. In this factory, rotary kiln and drying methods are used to produce clinker. Due to the proximity of the factory to the city and environmental considerations, the hybrid electro-filter is used and this causes the output cement dust to be reduced to less than $5 \mathrm{mg} / \mathrm{m}^{3}$.

Fig. 2 indicates the variation of some different physical and chemical properties of the soil around the cement factory with depth.

\subsection{Sampling Process}

In order to monitor the amount of heavy metals around Shiraz cement factory, 10 sampling sites were selected at a 100 and 200-m distance from the factory in the direction of prevailing wind and along the route of the cement transport vehicles (Fig. 1(c)). At these sites, the concentration of four heavy metals including $\mathrm{Cd}$, $\mathrm{Ni}, \mathrm{Pb}$, and $\mathrm{Al}$ in the soil was measured. It was tried to collect

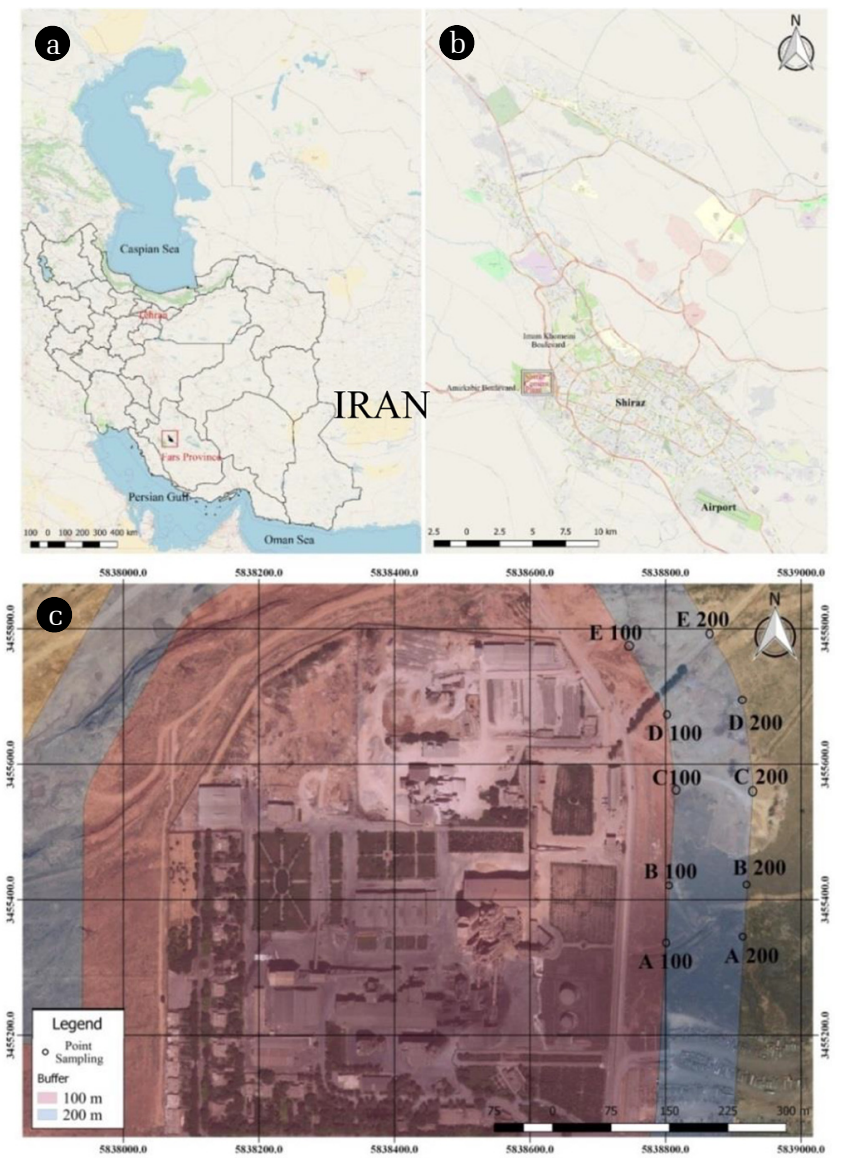

Fig. 1. Location of (a) Shiraz City in Iran, (b) study area in Shiraz City, and (c) sampling sites.

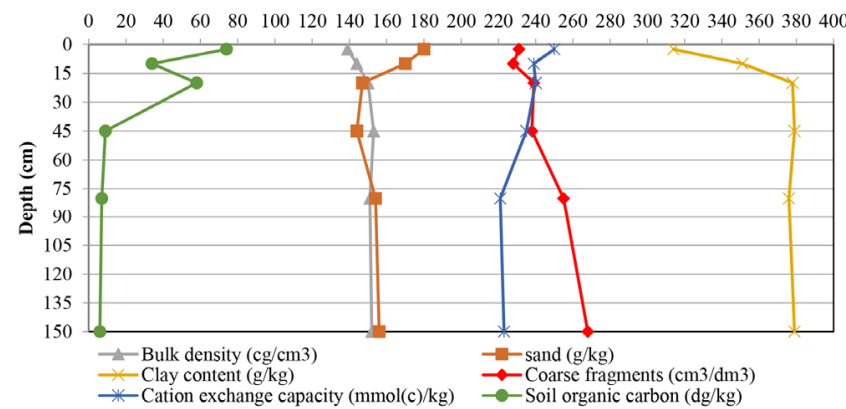

Fig. 2. The physical and chemical properties of the soil around Shiraz cement factory.

samples from areas with no vegetation cover to minimize the impact of plants on heavy metals concentration. Soil was sampled only once and quality control and quality assurance were applied in all stages of sample preparation, preservation and analysis. Soil samples were taken from the depth of $10-\mathrm{cm}$ using a plastic shovel and kept in plastic bags after removing large rocks and other foreign materials.

\subsection{Preparation and Analysis of Samples}

The concentration of heavy metals was measured in the Laboratory of Zagros Abshenas Fars according to ISIRI-11894 standard [26]. 
The samples were kept at room temperature to dry completely. Then, the soil samples were thoroughly crushed and passed through a 2-mm sieve. Then, $1 \mathrm{~g}$ of the screened sample was carefully weighed and digested with about $6-7$ cc of acidic solution (including $60 \%$ hydrofluoric acid, 30\% hydrochloric acid, and 10\% nitric acid) for $48 \mathrm{~h}$. It was then kept in a steam bath for $2 \mathrm{~h}$. During digestion, about $2.7 \mathrm{~g}$ of boric acid powder was added to the sample to eliminate the corrosive effects of hydrofluoric acid. Afterwards, the digested solution was passed through a filter paper and the sample volume was increased to $50 \mathrm{~mL}$ with distilled water. Finally, the concentration of heavy metals in the sample was determined with the atomic absorption spectrometer.

\subsection{Ecological Risk Indices}

In the present study, the indicators of EF, Igeo, and PLI were used to evaluate the ecological risk potential of heavy metals contamination in the soil of study area. These three indicators are described below.

\subsection{1. $\mathrm{EF}$}

The EF is used to evaluate the potential impact of human activities on the concentration of heavy metals in the topsoil [27]. This factor is a simple tool to assess the degree of enrichment in different soil samples and compare the pollution of heavy metals in different environments. In this method, a base metal such as $\mathrm{Al}, \mathrm{Mn}, \mathrm{Fe}$, Sc, Co, and Ti is used as a reference element to normalize the amount of other heavy metals [15]. The main reason for choosing one of these metals as a reference element is that the concentration of these metals in the soil is completely independent of the other heavy metals concentration. Therefore, $\mathrm{Al}$ was selected as a reference element in this study. The value of EF is computed using Eq. (1) as follows [21, 23, 28]:

$$
\mathrm{EF}=\left[\frac{\left(\frac{C_{m}}{C_{n}}\right) \text { sampls }}{\left(\frac{C_{m}}{C_{n}}\right) \text { background }}\right]
$$

where $\mathrm{C}_{\mathrm{m}}$ is the concentration of metal in the study medium (soil), $\mathrm{C}_{\mathrm{n}}$ is the concentration of reference metal (Al) for normalization, and background $\mathrm{C}_{\mathrm{m}}$ and $\mathrm{C}_{\mathrm{n}}$ are the concentration of the intended heavy metal and reference metal in a base medium (shell- Earth) , respectively [21, 23, 29]. In the Earth's crust, the mean concentration of $\mathrm{Al}$ as the reference metal is considered $82,000 \mathrm{ppm}(8.2 \%$ ) [30, 31]. Table 1 presents five EF"s levels for classifying the soil quality state. If the presence of a certain heavy metal in the soil is due to natural processes, the value of $\mathrm{EF}$ will be from 0.5 to 1.5. However, if heavy metal contamination is due to human activities, the EF value will exceed 1.5 [32-34].

Table 1. EF Values Classification [27]

\begin{tabular}{ll}
\hline Intensity of enrichment & \multicolumn{1}{c}{$\mathbf{E F}$} \\
Depletion or at least enrichment & $\mathrm{EF}<2$ \\
Moderate enrichment & $\mathrm{EF}=2-5$ \\
Severe enrichment & $\mathrm{EF}=5-20$ \\
Enrichment is very intense & $\mathrm{EF}=20-40$ \\
Extremely intense enrichment & $\mathrm{EF}>40$
\end{tabular}

\subsubsection{Igeo}

Another indicator for measuring soil contamination with heavy metals is the Igeo index or geo-accumulation index, which is used to determine the severity of pollution [35]. This index is calculated using Eq. (2) as follows:

$$
I_{g e o}=\log _{2}\left(\frac{C_{n}}{1.5 B_{n}}\right)
$$

where $C_{n}$ and $B_{n}$ is the concentration of metal in the soil sample and background sample, respectively. The coefficient of 1.5 is the correction factor of the background matrix due to lithological effects $[30,35,36]$. Based on the Igeo, the degree of soil contamination is divided into 7 categories (Table 2).

Table 2. Classification of Lgeo [27]

\begin{tabular}{lc}
\hline Degree of contamination & Igeo \\
\hline Uninfected & $<0$ \\
\hline Non-contaminated to slightly contaminated & $0-1$ \\
Slightly infected & $1-2$ \\
Slightly contaminated to very contaminated & $2-3$ \\
Very infected & $3-4$ \\
Very contaminated to highly contaminated & $4-5$ \\
Severely infected & $>5$ \\
\hline
\end{tabular}

\subsubsection{PLI}

The PLI index is also used to assess the overall degree of soil contamination. This index provides an easy way to prove the deterioration of soil conditions due to the accumulation of heavy metals [34]. In this index, the concentration of pollution is calculated using Eq. (3) as follows:

$$
\mathrm{PLI}=\sqrt[n]{\mathrm{CF} 1 \times \mathrm{CF} 2 \times \mathrm{CF} 3 \times \ldots \ldots \mathrm{CFn}}
$$

where $\mathrm{n}$ is the number of study heavy metals and the contamination factor (CFn) is the mean concentration of each heavy metal normalized by the concentration of the same metal in the reference soil (Eq. (4)).

$$
\mathrm{CF}=\frac{C_{\text {metal }}}{C_{\text {background }}}
$$

where $\mathrm{C}_{\text {metal }}$ and $\mathrm{C}_{\text {background }}$ are the mean concentration of the a heavy metal in the polluted soil and the reference soil, respectively. The values of PLI more than 1 indicate soil pollution [15, 22].

\section{Results and Discussion}

\subsection{Concentration of Heavy Metals in Soil Samples}

The mean $\mathrm{pH}$ of the soil around Shiraz cement factory was about 8.79 which indicates that the soil is alkaline. Different physical and chemical properties such as organic matter content, and $\mathrm{pH}$ have a significant impact on the mobility of heavy metals in the 

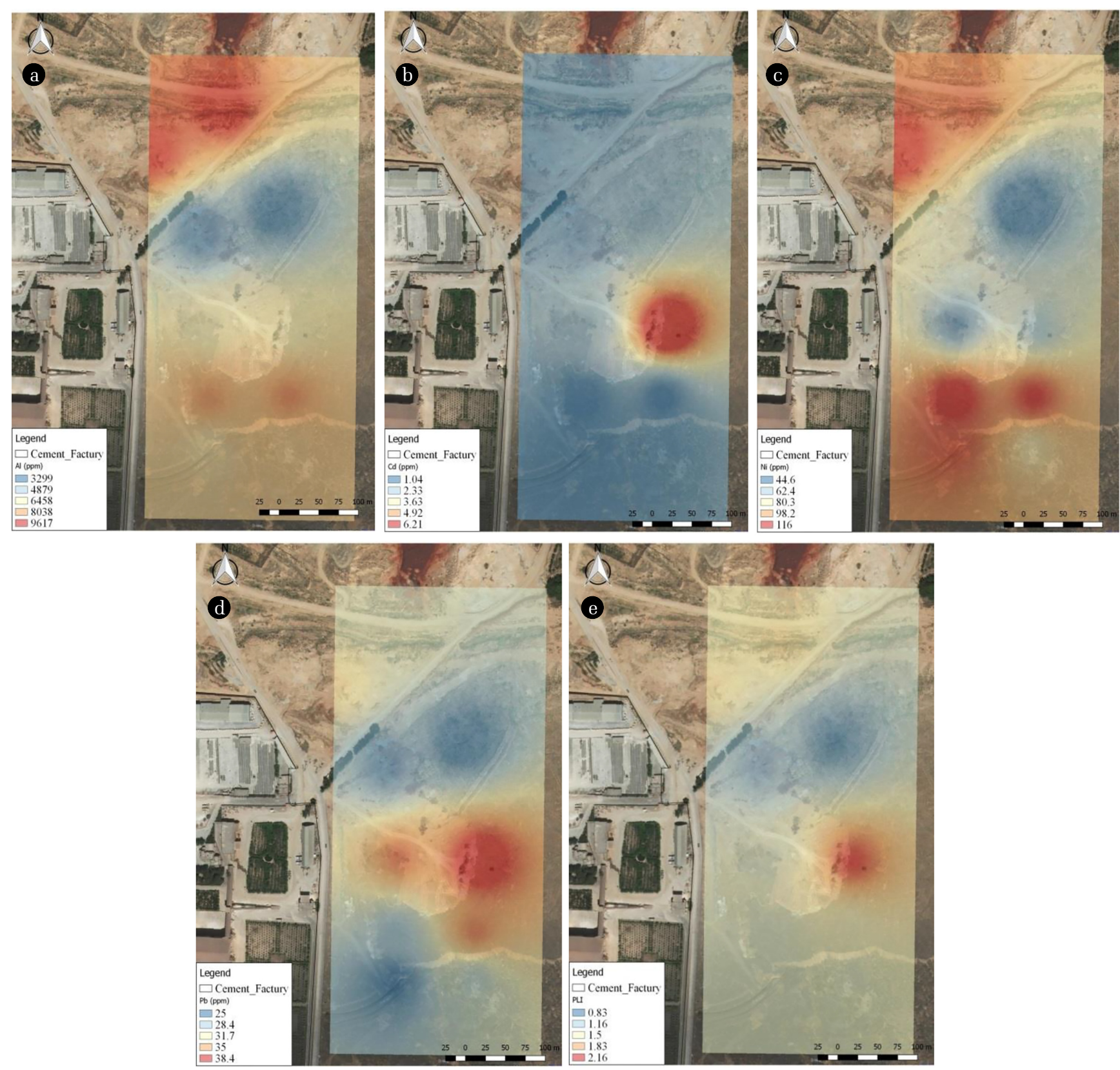

Fig. 3. Spatial distribution of (a) $\mathrm{Al}$, (b) $\mathrm{Cd}$, (c) $\mathrm{Ni}$, (d) Pb, (e) PLI in the study area.

soil especially in an area with high rainfall [33]. Table 3 presents the concentration of heavy metals in the soil samples around Shiraz cement factory and the mean concentration of heavy metals values in the regional and global shale. The concentration of heavy metals in the soil samples follows this trend: $\mathrm{Al}>\mathrm{Ni}>\mathrm{Pb}>\mathrm{Cd}$. The mean value of $\mathrm{Al}, \mathrm{Pb}, \mathrm{Cd}$, and $\mathrm{Ni}$ is $6,937.14,30.74,1.96$, and $88.09 \mathrm{ppm}$, respectively. These values are higher than the global shale and USEPA values [9, 37-39]. Therefore, the cement factory activities can be considered as the main source of heavy metal pollution in the study area. The minimum value of $\mathrm{Al}, \mathrm{Pb}$, and $\mathrm{Ni}$ was found in sample site D-200 located at a great distance from the factory and the routes of cement transport vehicles. The maximum value of $\mathrm{Pb}$ and $\mathrm{Cd}$ was measured in the sample siteC-200. This site is in the parking lot of cement transport vehicles which is also an area for surface runoff accumulation.

Fig. 3 shows the spatial distribution of $\mathrm{Ni}, \mathrm{Pb}, \mathrm{Cd}$, and $\mathrm{Al}$ in the vicinity of the Shiraz cement factory. As seen, the spatial distribution of each heavy metal is totally different and depends on the routes of the cement transport vehicles, the volume of traffic, surface runoff, and the prevailing wind direction. $\mathrm{Ni}$ and $\mathrm{Al}$ have a roughly similar spatial concentration distribution so that the maximum value was found in the north and south part of the 
Table 3. Concentration of Heavy Metals in the Sampling Sites

\begin{tabular}{|c|c|c|c|c|c|c|}
\hline Sampling Site & Distance (m) & pH & Al (ppm) & $\mathrm{Pb}(\mathrm{ppm})$ & Cd (ppm) & Ni (ppm) \\
\hline \multirow{2}{*}{ A } & 100 & 9.11 & 6855.65 & 24.90 & 1.30 & 110.25 \\
\hline & 200 & 8.61 & 7334.00 & 29.30 & 1.45 & 83.50 \\
\hline \multirow{2}{*}{ B } & 100 & 8.45 & 8365.85 & 27.80 & 0.80 & 124.00 \\
\hline & 200 & 8.48 & 8514.05 & 36.25 & 0.87 & 116.50 \\
\hline \multirow{2}{*}{$\mathrm{C}$} & 100 & 8.61 & 6336.35 & 36.60 & 1.85 & 48.50 \\
\hline & 200 & 8.77 & 6512.85 & 41.55 & 8.50 & 61.00 \\
\hline \multirow{2}{*}{$\mathrm{D}$} & 100 & 9.46 & 2686.65 & 24.55 & 1.10 & 73.00 \\
\hline & 200 & 9.54 & 2723.95 & 23.55 & 1.60 & 31.50 \\
\hline \multirow{2}{*}{$\mathrm{E}$} & 100 & 8.72 & $9,887.05$ & 32.35 & 0.94 & 124.15 \\
\hline & 200 & 8.16 & $10,154.95$ & 30.50 & 1.20 & 108.50 \\
\hline \multicolumn{2}{|l|}{ MIN } & 8.16 & $2,686.65$ & 23.55 & 0.80 & 31.50 \\
\hline \multicolumn{2}{|l|}{ MAX } & 9.54 & $10,154.95$ & 41.550 & 8.50 & 124.15 \\
\hline \multicolumn{2}{|c|}{ Standard deviation } & 0.45 & $2,584.3$ & 5.95 & 2.32 & 33.43 \\
\hline \multicolumn{2}{|c|}{ Mean } & 8.79 & $6,937.14$ & 30.74 & 1.96 & 88.09 \\
\hline \multicolumn{2}{|c|}{ World mean shale value (ppm) $[32,36,40]$} & - & 100 & 20 & 1 & 50 \\
\hline \multicolumn{2}{|c|}{ USEPA value(ppm) $[32,36]$} & - & - & 10 & 0.06 & 40 \\
\hline \multicolumn{2}{|c|}{ Holmgeren et al. [38] (mg/kg) } & - & - & 8.6 & 0.29 & 27.4 \\
\hline \multicolumn{2}{|c|}{ Boemgen \& shackette [37] (mg/kg) } & - & - & 16 & - & 16 \\
\hline
\end{tabular}

study area. Almost in the middle of the study area, which has been covered with vegetation, the concentration of heavy metals is lower than elsewhere.

\subsection{Investigating the Enrichment Index around the Study Area}

Table 4 presents the calculated EF values at the sampling sites around the cement factory. Results show that there is a moderate to very severe enrichment of heavy metals around the factory. In the study area, $\mathrm{Ni}$ and $\mathrm{Cd}$ with enrichment number of 2.96 and 29.25 have the minimum and maximum $\mathrm{EF}$ value, respectively. Since these values are greater than 1.5 the industrial activities related to cement production cause the environment to be polluted with heavy metals. In addition, the $\mathrm{Pb}$ pollution around the cement factory is relatively high which may be due to the activities of cement transport vehicles. However, differences in EF values may be due to the differences in the rate at which each metal enters the soil or is removed from the soil [37, 41]. Among sampling sites, B200 and D200 have the lowest and highest EF, respectively.

\subsection{Investigating Igeo around the Study Area}

Table 4 shows the Igeo index calculated for soil samples around the Shiraz cement factory. The results indicate that the surrounding soil has not polluted with $\mathrm{Al}$ and Ni elements. According to Table 2 , the mean Igeo for $\mathrm{Pb}$ and $\mathrm{Cd}$, which is 0.16 and 0.68 , respectively, demonstrates that these pollutants are in the range of non-contaminated to slightly contaminated. Moghtaderi et al. [23] examined the amount of Igeo for the whole soil of Shiraz City. They measured the amount of $\mathrm{Ni}$ at a $400-\mathrm{m}$ distance from Shiraz cement factory

Table 4. The Values of EF, Igeo, CF and PLI for Heavy Metals in the Soil Samples of the Study Area

\begin{tabular}{|c|c|c|c|c|c|c|c|c|c|c|c|c|c|}
\hline \multirow{2}{*}{$\begin{array}{l}\text { Sampling } \\
\text { site }\end{array}$} & \multirow{2}{*}{$\underset{\text { (m) }}{\text { Distance }}$} & \multicolumn{3}{|c|}{$\mathbf{E F}$} & \multicolumn{4}{|c|}{ Igeo } & \multicolumn{4}{|c|}{ CF } & \multirow[b]{2}{*}{ PLI } \\
\hline & & $\underset{(\mathrm{ppm})}{\mathrm{Ni}}$ & $\underset{(\mathbf{p p m})}{\mathrm{Cd}}$ & $\underset{(\mathrm{ppm})}{\mathrm{Pb}}$ & $\underset{(\mathbf{p p m})}{\mathrm{Ni}}$ & $\underset{(\mathbf{p p m})}{\mathbf{C d}}$ & $\underset{(\mathbf{p p m})}{\mathrm{Pb}}$ & $\underset{(\mathbf{p p m})}{\mathrm{Al}}$ & $\underset{(\mathbf{p p m})}{\mathrm{Ni}}$ & $\underset{(\mathbf{p p m})}{\mathrm{Cd}}$ & $\underset{(\mathbf{p p m})}{\mathrm{Pb}}$ & $\underset{(\mathbf{p p m})}{\mathrm{Al}}$ & \\
\hline \multirow{2}{*}{ A } & 100 & 0.56 & 26.55 & 7.26 & -0.04 & 0.64 & 0.07 & -0.79 & 1.38 & 6.5 & 1.77 & 0.24 & 1.40 \\
\hline & 200 & 0.40 & 27.68 & 7.99 & -0.16 & 0.68 & 0.14 & -0.76 & 1.04 & 7.25 & 2.09 & 0.26 & 1.42 \\
\hline \multirow{2}{*}{ B } & 100 & 0.52 & 13.39 & 6.65 & 0.01 & 0.42 & 0.12 & -0.70 & 1.55 & 4 & 1.98 & 0.29 & 1.37 \\
\hline & 200 & 0.48 & 14.31 & 8.51 & -0.01 & 0.46 & 0.24 & -0.69 & 1.46 & 4.35 & 2.58 & 0.30 & 1.48 \\
\hline \multirow{2}{*}{ C } & 100 & 2.68 & 40.87 & 11.55 & -0.39 & 0.79 & 0.24 & -0.82 & 0.61 & 9.25 & 2.61 & 0.22 & 1.34 \\
\hline & 200 & 3.28 & 0.46 & 12.76 & -0.29 & 1.45 & 0.30 & -0.81 & 0.76 & 42.5 & 2.96 & 0.23 & 2.16 \\
\hline \multirow{2}{*}{ D } & 100 & 9.51 & 57.32 & 18.28 & -0.21 & 0.46 & 0.07 & -1.19 & 0.91 & 5.5 & 1.75 & 0.09 & 0.94 \\
\hline & 200 & 4.05 & 82.23 & 17.29 & -0.58 & 0.73 & 0.05 & -1.19 & 0.93 & 8 & 1.68 & 0.09 & 0.83 \\
\hline \multirow{2}{*}{$\mathrm{E}$} & 100 & 4.39 & 13.24 & 6.54 & 0.01 & 0.49 & 0.19 & -0.63 & 1.55 & 4.67 & 2.31 & 0.35 & 1.55 \\
\hline & 200 & 3.74 & 16.54 & 6.01 & -0.04 & 0.60 & 0.16 & -0.62 & 1.36 & 6 & 2.17 & 0.36 & 1.58 \\
\hline Mean & & 2.96 & 29.25 & 10.25 & -0.17 & 0.68 & 0.16 & -0.82 & 1.10 & 9.80 & 2.19 & 0.24 & 1.40 \\
\hline
\end{tabular}


and found that the soil was in the moderate to low condition in terms of ecological risk. In their study, the result of the Igeo is in good agreement with the results of this study.

\subsection{Investigating PLI around the Study Area}

PLI used to assess the overall effects of the cement factory on the soil and the toxicity degree of heavy metals in the soil (Table 4). Based on the results, the $\mathrm{Cd}$ and $\mathrm{Pb}$ with PLI value of 9.80 and 2.19, respectively, have the maximum contribution to heavy metal pollution in the study under. The mean PLI value is 1.4 and indicates the relative pollution of the soil around the factory with heavy metals. The minimum PLI (i.e. 0.83) in soil samples around the factory is observed at sampling site D200. The maximum value of PLI is 2.16 and belongs to sampling site C200 which is mainly due to heavy traffic of cement transport vehicles as well as the upstream runoff accumulation in this area. Therefore, it is suggested to create a pond at sampling site C200 to manage surface runoff as well as employ measures for the treatment of polluted soil. Fig. 3(e) shows the spatial distribution of this index. Table 5 shows the overall results of the indices used to assess the pollution of various heavy metals in the study area. As observed, the Cd has higher contamination load and more ecological effects in comparison to other heavy metals in the study area. The main reason of the Cd entry into the around topsoil is to smelt and refine ores and fossil fuels as well as other types of cement factory processes that easily cause $\mathrm{Cd}$ to be released into the atmosphere with dust and settle on the adjacent soil surface

Table 5. Numerical Value of Indicators for the Study Elements

\begin{tabular}{cccc}
\hline $\begin{array}{c}\text { Indicators } \\
\text { Elements }\end{array}$ & $\mathbf{E F}$ & Igeo & PLI \\
\hline $\mathrm{Ni}$ & 2.96 & -0.17 & 1.10 \\
\hline $\mathrm{Cd}$ & 29.25 & 0.68 & 9.80 \\
\hline $\mathrm{Pb}$ & 10.28 & 0.16 & 2.19 \\
\hline $\mathrm{Al}$ & & -0.82 & 0.24 \\
\hline
\end{tabular}

\section{Conclusions}

In this study, the concentration of $\mathrm{Al}, \mathrm{Pb}, \mathrm{Cd}$, and $\mathrm{Ni}$ in the topsoil around the Shiraz cement factory was examined, and the ecological and environmental risks of heavy metals were assessed using Igeo, $\mathrm{EF}$, and PLI. Based on the results, the Cd has higher contamination load and more adverse ecological effects in comparison to $\mathrm{Ni}, \mathrm{Pb}$, and $\mathrm{Al}$ in the study area. While the topsoil around the factory was unpolluted to moderately polluted in terms of Igeo, the index of EF showed that the effect of anthropogenic activities are considerable in the study area.

The spatial distribution of heavy metals concentration showed that the highest pollution load is in the parking lot of cement transport vehicles which is also an area for surface runoff accumulation. The results of this study offer useful information about the adverse effects of cement factories on topsoil in terms of heavy metals pollution.

\section{Author Contributions}

H.A. (Ph.D.) conducted all the experiments and wrote the manuscript. E.D. (Master Student) experimental work. S.A. (Assistant Professor) wrote and revised the manuscript. S.A. (Master degree) revised the manuscript.

\section{References}

1. Yalcin MG, Battaloglu R, Ilhan S. Heavy metal sources in Sultan Marsh and its neighborhood, Kayseri, Turkey. Environ. Geol. 2007;53(2):399-415.

2. Tamadoni A, Qaderi F. Environmental-economical assessment of the use of ultrasonication for pre-treatment of the soils contaminated by phenanthrene. J. Environ. Manag. 2020;259: 109991.

3. Qaderi F, Sayahzadeh A, Azizpour F, Vosughi P. Efficiency modeling of serial stabilization ponds in treatment of phenolic wastewater by response surface methodology. Int. J. Environ. Sci. Technol. 2019;16(8):4193-4202.

4. Yahaya T, Okpuzor J, Ajayi T. The protective efficacy of selected phytonutrients on liver enzymes of albino rats exposed to cement dust. IOSR J. Pharm. Biol. Sci. 2013;8(3):38-44.

5. Atmospheric environmentAbu-Allaban M., Abu-Qudais H., Impact assessment of ambient air quality by cement industry: A case study in Jordan. Aerosol Air Qual. Res. 2011;11(7): 802-810.

6. Moslempour ME, Shahdadi S. Assessment of heavy metal contamination in soils around of Khash Cement Plant, SE Iran. Iran. J. Earth Sci. 2013;5(2):111-118.

7. Ogunkunle CO, Fatoba PO. Pollution Loads and the Ecological Risk Assessment of Soil Heavy Metals around a Mega Cement Factory in Southwest Nigeria. Pol. J. Environ. Stud. 2013;22(2): 487-493.

8. Kabata-Pendias A. Trace elements in soils and plants. $4^{\text {th }} \mathrm{ed}$. CRC press; 2010. p. 273-315.

9. Kabata-Pendias A, Mukherjee AB. Trace elements from soil to human. Springer Science \& Business Media; 2007. p. 87-225.

10. Al-Oud S, Nadeem M, Al-Shbel B. Distribution of heavy metals in soils and plants around a cement factory in Riyadh city, central of Saudi Arabia. Am. Eurasian J. Agric. Environ. Sci. 2011;11(2):183-191.

11. Okedeyi OO, Dube S, Awofolu OR, Nindi MM. Assessing the enrichment of heavy metals in surface soil and plant (Digitaria eriantha) around coal-fired power plants in South Africa. Environ. Sci. Pollut. 2014;21(6):4686-4696.

12. Odoh R, Archibong C, Anidobu C. Heavy metals profile and variations of soil properties in a vicinity of cement factory in Obajana in Kogi State of Nigeria. Int. J. Adv. Res. Chem. Sci. 2018;5(8):5-13.

13. Zheng N, Liu J, Wang Q, Liang Z. Health risk assessment of heavy metal exposure to street dust in the zinc smelting district, Northeast of China. Sci. Total Environ. 2010;408(4):726-733.

14. Shi G, Chen Z, Bi C, et al. A comparative study of health risk of potentially toxic metals in urban and suburban road dust in the most populated city of China. Atmos. 2011;45(3): 
764-771.

15. Addo M, Darko E, Gordon C, et al. Evaluation of heavy metals contamination of soil and vegetation in the vicinity of a cement factory in the Volta Region, Ghana. Int. J. Sci. Technol. 2012;2:40-50.

16. Shahhoseiny M, Ardejani FD, Shafaei SZ, Noaparast M, Hamidi D. Geochemical and mineralogical characterization of a pyritic waste pile at the Anjir Tangeh coal washing plant, Zirab, Northern Iran. Mine Water Environ. 2013;32(2):84-96.

17. Burges A, Epelde L, Garbisu C. Impact of repeated single-metal and multi-metal pollution events on soil quality. Chemosphere 2015;120:8-15.

18. Zhang J, Hua P, Krebs P. Influences of land use and antecedent dry-weather period on pollution level and ecological risk of heavy metals in road-deposited sediment. Environ. Pollut. 2017;228:158-168.

19. Pratush A, Kumar A, Hu Z. Adverse effect of heavy metals (As, $\mathrm{Pb}, \mathrm{Hg}$, and $\mathrm{Cr}$ ) on health and their bioremediation strategies: a review. Int. J. Microbiol. 2018;21(3):97-106.

20. Kowalska JB, Mazurek R, Gąsiorek M, Zaleski T. Pollution indices as useful tools for the comprehensive evaluation of the degree of soil contamination-A review. Environ. Geochem. Health. 2018;40(6):2395-2420.

21. Olatunde K, Sosanya P, Bada B, Ojekunle Z, Abdussalaam S. Distribution and ecological risk assessment of heavy metals in soils around a major cement factory, Ibese, Nigeria. Sci. African. 2020;9:e00496.

22. Laniyan TA, Adewumi AJ. Evaluation of contamination and ecological risk of heavy metals associated with cement production in Ewekoro, Southwest Nigeria. J. Health Pollut. 2020;10(25):200306.

23. Moghtaderi T, Alamdar R, Rodríguez-Seijo A, Naghibi SJ, Kumar V. Ecological risk assessment and source apportionment of heavy metal contamination in urban soils in Shiraz, Southwest Iran. Arab. J. Geosci. 2020;13(16):1-12.

24. Jahandari A, Abbasnejad A, Jamasb R. Concentration, likely sources, and ecological risk assessment of potentially toxic elements in urban soils of Shiraz City, SW Iran: a preliminary assessment. Arab. J. Geosci. 2020;13(18):1-10.

25. Sayadi M, Sayyed M, Comparative assessment of baseline concentration of the heavy metals in the soils of Tehran (Iran) with the comprisable reference data. Environ. Earth Sci. 2011;63(6):1179-1188.

26. Agency U.E.P. Guidelines for the health risk assessment of chemical mixtures. Fed. Reg. 1986;51(185):34014-34025.

27. Barbieri M., The importance of enrichment factor (EF) and geoaccumulation index (Igeo) to evaluate the soil contamination.
J. Geol. Geophys. 2016;5(1):1-4.

28. Ahamad MI, Song J, Sun H, et al. Contamination level, ecological risk, and source identification of heavy metals in the hyporheic zone of the Weihe River, China. Int. J. Environ. Res. Public Health. 2020;17(3):1070.

29. Teng Y, Huang C.-Y, Long J, Yao H.-Y. Studies on soil enzymatic activities in areas contaminated by tailings from $\mathrm{Pb}, \mathrm{Zn}, \mathrm{Ag}$ mine. China Environ. Sci. 2002;22(6):551-555.

30. Bowen HJM. Environmental chemistry of the elements. 3th ed. London; Academic Press; 1979. p. 181-247.

31. Wang XS. Magnetic properties and heavy metal pollution of soils in the vicinity of a cement plant, Xuzhou (China). Appl. Geophys. 2013;98:73-78.

32. Zhang J, Liu C. Riverine composition and estuarine geochemistry of particulate metals in China - weathering features, anthropogenic impact and chemical fluxes. Estuar. Coast. Shelf Sci. 2002;54(6):1051-1070.

33. Varol M. Assessment of heavy metal contamination in sediments of the Tigris River (Turkey) using pollution indices and multivariate statistical techniques. J. Hazard. Mater. 2011;195: 355-364.

34. Shayestefar M, Rezaei A. The study of environmental behavior and the investigation of heavy metals distribution in the soils of the Sarcheshmeh copper mine area of Kerman. Iranian J. Min. Eng. 2013;8(18):13-21.

35. Ying L, Zitong G, Ganlin Z. The chemical speciation of heavy metals of urban soil in Nanjing. Environ. Chem. 2003;22(2): 131-136.

36. Odewande AA, Abimbola AF. Contamination indices and heavy metal concentrations in urban soil of Ibadan metropolis, southwestern Nigeria. Environ. Geochem. Health. 2008;30(3):243-254.

37. Boerngen JG, Shacklette HT. Chemical analyses of soils and other surficial materials of the conterminous United States: U.S. Geological Survey Open-File Report 81-197, U.S. Geological Survey, Denver, CO; 1981. p. 81-197.

38. Holmgren G, Meyer M, Chaney R, Daniels R. Cadmium, lead, zinc, copper, and nickel in agricultural soils of the United States of America. J. Environ. Qual. 1993;22(2):335-348.

39. Charkhabi AH, Sakizadeh M, Rafiee G. Seasonal Fluctuation in Heavy Metal Pollution in Iran s Siahroud River-A Preliminary Study (7 pp). Environ. Sci. Pollut. 2005;12(5):264-270.

40. Muller G. Index of geoaccumulation in sediments of the Rhine River. Geojournal 1969;2:108-118.

41. Akoto O, Ephraim J, Darko G. Heavy metals pollution in surface soils in the vicinity of abundant railway servicing workshop in Kumasi, Ghana. Int. J. Environ. Res. 2008;2(4):359-364. 